\title{
EDITORIAL
}

\section{Tumour necrosis factor and lymphotoxin A polymorphisms: a relationship with COPD and its progression?}

\author{
H.M. Boezen* and D.S. Postma\#
}

n $\mathrm{n}$ this issue of the European Respiratory Journal, TANAKA et al. [1] present the results of their study on polymorphisms in tumour necrosis factor (TNF) and lymphotoxin A (LTA) in relation to lung function in smokers. They designed two nested case-control studies in the Lung Health Study, originally enrolling almost 6,000 smokers with mild-to-moderate chronic obstructive pulmonary disease (COPD). They conclude that there exist no significant associations between polymorphisms in TNF or LTA and lung function in COPD patients of Caucasian origin, contrary to previously reported studies in Asians. It is important to note that this study assesses the genetics of progression of COPD and that the study cannot make any inference from this population as to whether the genes under study are COPD susceptibility genes. To meet this aim, one needs a general population study in which smokers with and without accelerated lung function loss are compared.

These findings are of importance, since they confirm and extend previously reported negative findings in Caucasians; among them is one of the authors' own studies that included only two polymorphisms in the genes [2]. In the present study, the authors analyse a sample that is sufficiently large to exclude potential negative findings due to small study populations, and thus lack of power. Indeed, one of the strengths of the study by TANAKA et al. [1] is the a priori power calculation, to ensure a sufficiently large sample to detect differences in distributions of polymorphisms between their COPD subgroups.

Unfortunately, too many studies on genetics of COPD are still being performed in COPD patients derived from population samples investigators happen to have at hand, including patients with inappropriately defined COPD phenotypes. This increases the likelihood of spurious results, since genotyping in excessively small sample sizes will lead to positive results in a pre-defined number of studies (e.g. $5 \%$, if $\alpha=0.05$ is accepted). Thus, it is not surprising that a fair amount of positive results from genetic studies of COPD have not been replicated in similar or even larger populations. There is another reason

*Depts of Epidemiology and ${ }^{\#}$ Pulmonology, University Medical Center Groningen, University of Groningen, Groningen, The Netherlands.

CORRESPONDENCE: D.S. Postma, University Medical Center Groningen, Dept Pulmonary Diseases, Hanzeplein 1, 9713 GZ Groningen, The Netherlands. Fax: 31 503619320. E-mail: d.s.postma@int. umcg.nl why it is important to publish (negative) studies like that of TANAKA et al. [1]. There may be an unjustified bias towards lack of publication of negative findings, and moreover it is necessary to discover that previously reported findings are unjustly called positive. Presumably, reviewers and journals are more likely to accept first-time positive findings than firsttime negative findings. As for researchers, in order to prove that previous positive findings are in fact negative, large efforts and costs are required, since one needs a study sample that is easily three or four times as large as the one from the original study [3].

Another potential drawback of current genetic research practice also surfaces in the study of TANAKA et al. [1], namely the apparent difficulties of transposing results from one population to another. Findings in Asians are often not replicated in Caucasian subjects. True associations found in Asians may be missed in Caucasian populations as a result of different, usually lower, prevalences of the polymorphisms under study in Caucasian subjects. However, this explanation might be too simple. If the decision to study a particular gene is based on biological plausibility or homology with other diseases, one would expect that the majority of positive associations reported in Asians could be replicated in Caucasian subjects, assuming that the function of the polymorphism under study is the same in different races. Clearly, this presumption automatically stresses the importance of thorough research on the functionality of polymorphisms that have been found to be positively associated with COPD. In our opinion, this type of research will be crucially important for further understanding the pathophysiological processes that evolve in the pathway from genetics to phenotypic expression of COPD.

Apart from insufficiently large population samples, differences in the definition of the exact phenotypic outcome under study may also lead to difficulties in replicating results. A strength of the study of TANAKA et al. [1] is that the authors clearly define COPD in two ways, and study these phenotypic outcomes in two different nested case-control samples. First, they compare (a sample of) subjects with the fastest and the slowest lung function decline. Secondly, they compare subjects with the highest and lowest post-bronchodilator \% predicted forced expiratory volume in one second (FEV1). Fortunately, both nested case-control samples are mutually exclusive, since one might expect a number of subjects who have the fastest decline 
TABLE 1 Studies investigating links between tumour necrosis factor (TNF), lymphotoxin A (LTA) and chronic obstructive pulmonary disease (COPD)

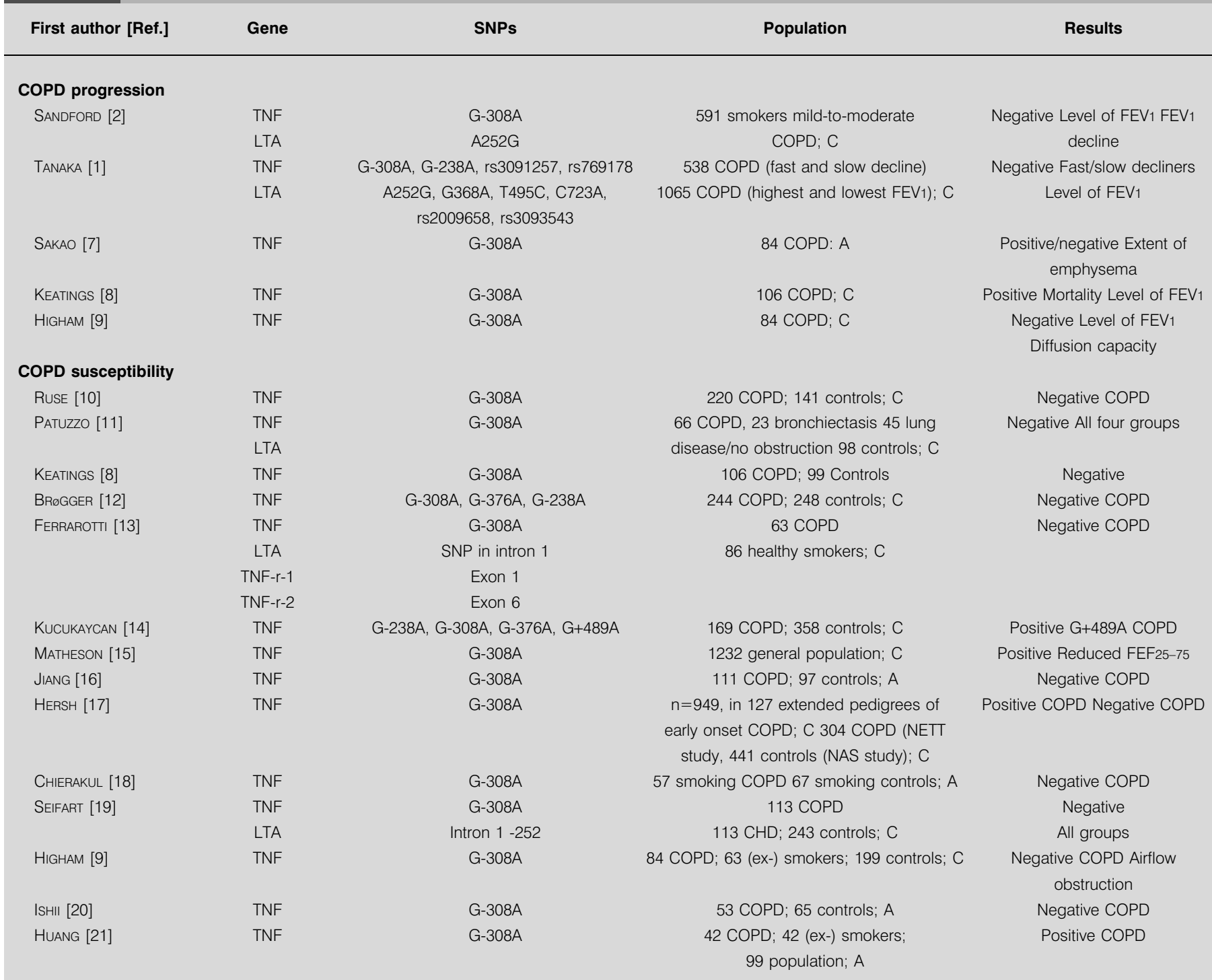

SNPs: single nucleotide polymorphisms; C: Caucasians; FEV1: forced expiratory volume in one second; A: Asians; FEF25-75: forced expiratory flow between 25 and $75 \%$ of forced vital capacity.

to have the lowest post-bronchodilator \% pred FEV1. Indeed, the authors indicate there was an overlap of $\sim 25 \%$ between the two groups. However, the mutual exclusion of the two nested case-control samples does not withhold the fact that both COPD phenotypes might be highly correlated, and therefore the two different outcomes are not as "different" as might be suspected at first glance. Thus, the study would have gained in relevance if the cross-sectional (nested) case-control analyses had been extended to longitudinal analyses. This would have given insight into the potential (lack of) association of single nucleotide polymorphisms (SNPs) in the continuous range of lung function. Clearly, information about the potential (lack of) association between SNPs and lung function should preferably not be reduced to lack of associations in the extremes of the lung function continuum, but cover the whole range of lung functions in-between, representing a different phenotype to that of the extreme lung function decliners. Our own studies in a very large general population cohort showed that it is important to study both high excess decline and no decline, as TANAKA et al. [1] did, as well as decline in lung function over the years, since both phenotypes may be different expressions of disease, and important associations may be identified studying the whole continuum of lung function $[4,5]$.

It is important to note that TANAKA et al. [1] studied the association between TNF and LTA and COPD progression in a cohort of smokers and ex-smokers. Phenotypic expression of COPD in smokers may be different from phenotypic expression of COPD in nonsmokers, although the latter group is hardly ever studied. Although it is generally accepted that the 
majority of COPD patients are smokers or ex-smokers, pulmonologists observe subjects who claim they have never smoked in their life but who have developed COPD. It is possible that within this type of subject, genes other than those that are important for the development of COPD in smokers play a role. Therefore, we advocate additional studies on the genetics of COPD in these subjects, probably in relation to environmental exposures, since a majority of these neversmokers who have developed COPD might be passive smokers.

The Lung Health Study [6] has collected unique longitudinal data on lung function of (ex-) smokers, including detailed information on whether individuals quit or sustained smoking over many years. This allows study of the effect of quitting versus sustained smoking on the course of lung function. Across the 5-yr follow-up period, among sustained quitters, females gained more in \% pred FEV1 than males [6]. Thus, smoking cessation has an even clearer advantage for females than it does for males. Therefore, analyses stratified according to sex, investigating the effects of TNF or LTA polymorphisms in quitters and sustained smokers, might yield important information about pathophysiological mechanisms underlying the sex differences in susceptibility to cigarette smoke.

In conclusion, TANAKA et al. [1] report, contrary to previously reported positive studies in Asians on chronic obstructive pulmonary disease susceptibility, a lack of association between tumour necrosis factor or lymphotoxin A and lung function progression in patients with mild-to-moderate chronic obstructive pulmonary disease in Caucasian subjects. The sample size and methodology of this study suggest that we can finally conclude that there is no association within white subjects. Reading various other papers on the subject with conflicting results (clearly not all quoted by TANAKA et al. [1]; table 1), tumour necrosis factor and lymphotoxin A could still be given the benefit of doubt as candidate genes for the development of chronic obstructive pulmonary disease in other populations.

\section{REFERENCES}

1 Tanaka G, Sandford AJ, Burkett K, et al. Tumour necrosis factor and lymphotoxin A polymorphisms and lung function in smokers. Eur Respir J 2007; 29: 34-41.

2 Sandford AJ, Chagani T, Weis TD, Connett E, Anthonisen NR, Pare PD. Susceptibility genes for rapid decline of lung function in the Lung Health Study. Am J Respir Crit Care Med 2001; 163: 469-473.

3 Palmer LJ, Cardon LR. Shaking the tree: mapping complex disease genes with linkage disequilibrium. Lancet 2005; 366: $1223-1234$.

4 van Diemen CC, Postma DS, Vonk JM, Bruinenberg M, Schouten JP, Boezen HM. A disintegrin and metalloprotease 33 polymorphisms and lung function decline in the general population. Am J Respir Crit Care Med 2005; 172: 329-333.

5 van Diemen CC, Postma DS, Boezen HM. Polymorphisms in MMPs and accelerated decline in FEV1 in the general population. Proc Am Thorac Soc 2006; 3: A543.

6 Connett JE, Murray RP, Buist AS, et al. Lung Health Study Research Group Changes in smoking status affect women more than men: results of the Lung Health Study. Am J Epidemiol 2003; 157: 973-979.

7 Sakao S, Tatsumi K, Igari $\mathrm{H}$, et al. Association of tumor necrosis factor- $\alpha$ gene promoter polymorphism with low attenuation areas on high-resolution CT in patients with COPD. Chest 2002; 122: 416-420.

8 Keatings VM, Cave SJ, Henry MJ, et al. A polymorphism in the tumor necrosis factor- $\alpha$ gene promoter region may predispose to a poor prognosis in COPD. Chest 2000; 118: 971-975.

9 Higham MA, Pride NB, Alikhan A, Morrell NW. Tumour necrosis factor- $\alpha$ gene promoter polymorphisms in chronic obstructive pulmonary disease. Eur Respir J 2000; 15: 281-284.

10 Ruse CE, Hill MC, Tobin M, et al. Tumour necrosis factor gene complex polymorphisms in chronic obstructive pulmonary disease. Respir Med 2006; [Epub ahead of print PMID: 16867312].

11 Patuzzo C, Gile LS, Zorzetto M, et al. Tumor necrosis factor gene complex in COPD and disseminated bronchiectasis. Chest 2000; 17: 1353-1358.

12 Brøgger J, Steen VM, Eiken HG, Gulsvik A, Bakke P. Genetic association between COPD and polymorphisms in TNF, ADRB2 and EPHX1. Eur Respir J 2006; 27: 682-688.

13 Ferrarotti I, Zorzetto $M$, Beccaria $M$, et al. Tumour necrosis factor family genes in a phenotype of COPD associated with emphysema. Eur Respir J 2003; 21: 444-449.

14 Kucukaycan M, Van Krugten M, Pennings HJ, et al. Tumor necrosis factor $-\alpha+489 \mathrm{G} / \mathrm{A}$ gene polymorphism is associated with chronic obstructive pulmonary disease. Respir Res 2002; 3: 29.

15 Matheson MC, Ellis JA, Raven J, Walters EH, Abramson MJ. Association of IL8, CXCR2 and TNF- $\alpha$ polymorphisms and airway disease. J Hum Genet 2006; 51: 196-203.

16 Jiang L, He B, Zhao MW, Ning LD, Li XY, Yao WZ. Association of gene polymorphisms of tumour necrosis factor- $\alpha$ and interleukin-13 with chronic obstructive pulmonary disease in Han nationality in Beijing. Chin Med J 2005; 118: 541-547.

17 Hersh CP, DeMeo DL, Lange C, et al. Attempted replication of reported chronic obstructive pulmonary disease candidate gene associations. Am J Respir Cell Mol Biol 2005; 33: 71-78.

18 Chierakul N, Wongwisutikul P, Vejbaesya S, Chotvilaiwan K. Tumor necrosis factor- $\alpha$ gene promoter polymorphism is not associated with smoking-related COPD in Thailand. Respirology 2005; 10: 36-39.

19 Seifart C, Dempfle A, Plagens A, et al. TNF- $\alpha-$, TNF- $\beta-$, IL6-, and IL-10 promoter polymorphisms in patients with chronic obstructive pulmonary disease. Tissue Antigens 2005; 65: 93-100.

20 Ishii T, Matsuse T, Teramoto S, et al. Neither IL-1 $\beta$, IL-1 receptor antagonist, nor TNF- $\alpha$ polymorphisms are associated with susceptibility to COPD. Respir Med 2000; 94: 847-851.

21 Huang SL, Su CH, Chang SC Tumor necrosis factor- $\alpha$ gene polymorphism in chronic bronchitis, Am J Respir Crit Care Med 1997; 156: 1436-1439. 